\title{
Dietary agents for chemoprevention of prostate cancer
}

\author{
Deeba N Syed, Yewseok Suh, Farrukh Afaq, and Hasan Mukhtar \\ Department of Dermatology, University of Wisconsin, Madison, Wisconsin, USA
}

\begin{abstract}
Prostate cancer $(\mathrm{CaP})$ is the leading cause of cancer-related deaths in American men, responsible for over 29,000 deaths in the year 2007. Chemoprevention is a plausible and cost-effective approach to reduce cancer morbidity and mortality through inhibition of precancerous events before the occurrence of clinical disease. Indeed, $\mathrm{CaP}$ is an ideal candidate disease for chemopreventive intervention as it is typically diagnosed in the elderly population with a relatively slower rate of growth and progression. The potential of dietary substances to act as chemopreventive agents against $\mathrm{CaP}$ is increasingly appreciated. Furhter, epidemiological studies have identified significant correlations between $\mathrm{CaP}$ incidence and dietary habits. It is hoped that, combining the knowledge based on agents with targets, we will be able to build an armamentarium of naturally occurring chemopreventive substances that could prevent or slow down the development and progression of $\mathrm{CaP}$. In this review, we have summarized the findings from clinical and preclinical studies on dietary agents including green tea, pomegranate, lupeol, fisetin and delphinidin that are currently being investigated in our laboratory for their chemopreventive potential against $\mathrm{CaP}$.
\end{abstract}

\section{Keywords}

Chemoprevention; Prostate cancer; Dietary agents

\section{Introduction}

According to the American Cancer Society, $\mathrm{CaP}$ accounts for 29 percent of all new cancer diagnoses in men and has surpassed heart disease as the top killer of men over the age of 85 years in the United States. The number of new cases projected to be diagnosed in the United States alone in 2007 was estimated at 218,890, with 27,000 deaths expected from the disease [1] suggesting that about 1 in 6 men will be diagnosed with $\mathrm{CaP}$ during his lifetime, out of which 1 in 34 will die of the disease. In addition, similar trends have been observed in most industrialized Western countries.

The process of $\mathrm{CaP}$ development is a consequence of genetic and epigenetic alterations that transform normal glandular epithelium to preneoplastic lesions and on to invasive carcinoma. Chemoprevention generally is defined as the use of specific agents to block or delay the process of carcinogenesis, thereby preventing the development of invasive cancer.

(C) 2008 Elsevier Ireland Ltd. All rights reserved.

Send correspondence to: Hasan Mukhtar, Ph.D., Helfaer Professor of Cancer Research, Director and Vice Chair of Research, Department of Dermatology, University of Wisconsin, Medical Sciences Center, Room \#B25, 1300 University Avenue, Madison, WI 53706. Phone: (608) 263-3927; Fax: (608) 263-5223, hmukhtar@wisc.edu.

Publisher's Disclaimer: This is a PDF file of an unedited manuscript that has been accepted for publication. As a service to our customers we are providing this early version of the manuscript. The manuscript will undergo copyediting, typesetting, and review of the resulting proof before it is published in its final citable form. Please note that during the production process errors may be discovered which could affect the content, and all legal disclaimers that apply to the journal pertain. 
We define chemoprevention as slowing the process of carcinogenesis. The goal of $\mathrm{CaP}$ chemoprevention research is to find agents that modulate the progression from normal epithelium to clinically significant and localized cancer, and also prevent the progression from localized cancer to locally advanced, to metastatic, to hormone refractory cancer. It is now recognized that cancer chemoprevention can be achieved by targeting various cell processes. Blocking the formation of the ultimate carcinogen, detoxification through phase I and phase II metabolic enzymes, inhibition of DNA-carcinogen adduct formation, enhanced DNA repair, and modulation of enzymes are some of the target processes of chemoprevention [2]. In addition, agents may exert their effect through scavenging oxygen radicals, inhibiting polyamine metabolism or regulation of signal transduction pathways, hormones, growth factors, or target receptors present in the cells [2]. Restoration of immune response, induction of apoptosis, inhibition of angiogenesis, preventing basement membrane degradation, and activation of antimetastasis genes are other mechanisms through which chemopreventive agents may act to retard the growth of tumor cells [2].

The molecular pathology of prostate cancer is complex; not only are multiple genes involved in its pathogenesis, but additional environmental factors such as diet and inflammation are also involved. Although epidemiologically $\mathrm{CaP}$ can be divided into hereditary and sporadic forms, most CaPs seem to be sporadic with $<10 \%$ inherited. In addition, it is not possible to distinguish between these two groups at the molecular level. Even though possible inherited $\mathrm{CaP}$ susceptibility genes such as the ELAC2, RNASEL, MSR1, NSB1, and CHEK2 genes have been identified in some families, the proportion of cases of hereditary $\mathrm{CaP}$ attributable to germline mutations in these loci is small [3]. Racial and ethnic differences in $\mathrm{CaP}$ incidence and mortality are well recognized, with African-American men being at the greatest risk for diagnosis, followed by Caucasian and Hispanic men while the Asian Americans seem to be at the lowest risk for CaP. Furthermore, marked geographic variations have been observed in the incidence of clinical $\mathrm{CaP}$, with higher rates in the North America and northern Europe, intermediate in Mediterranean region, and relatively low in many parts of Asia. Asian immigrants, who adopt a Western diet, show an increased incidence in $\mathrm{CaP}$, thought to be related to environmental factors and variations in dietary pattern [4]. In addition, there is evidence that increased consumption of selenium, vitamins $\mathrm{E}$ and D, lycopene, soy and isoflavonoids, green tea and low-fat diet reduce the risk of prostatic cancer. In fact, there is extensive data on the role of dietary agents against $\mathrm{CaP}$ in the literature, an area of research we recently review. In this mini-review, we have focused on the potential chemopreventive role of dietary agents that are being investigated in our laboratory (table 1).

\subsection{Green Tea}

Tea produced from the leaves of the plant Camellia sinensis is, next to water, the most widely consumed beverage in the world. Alterations in the manufacturing process result in black, green, and oolong tea, which account for approximately $75 \%, 23 \%$, and $2 \%$ of the global production, respectively. Even though each of these nonherbal teas is derived from the same source, different processing techniques render them chemically different from each other [5]. Thus, black tea contains more complex antioxidants called theaflavins and thearubigins, while steamed and parched green tea is rich in the chemically simpler antioxidants called catechins. In fact, green tea has been used in traditional Chinese medicine for centuries to treat and prevent chronic diseases, but it is only recently that it is being recognized as an effective chemopreventive agent against various cancers. [6]. The catechins or the flavonols present in green tea are the epicatechin, epigallocatechin, epicatechin-3-gallate, and epigallocatechin-3-gallate (EGCG), of which the latter has gained the most attention with respect to its chemopreventive and potential anticarcinogenic activity. EGCG constitutes up to $50 \%$ of the total catechin content and has a higher 
antioxidant activity than vitamins C and E. EGCG treatment has been shown to result in the induction of apoptosis in LNCaP, DU145, and PC-3 CaP cells. In addition, EGCG inhibits cellular proliferation primarily through the induction of $\mathrm{G} 1$ phase cyclin kinase inhibitors (cki), which inhibits the cyclin-cdk complexes operative in the G0/G1 phase of the cell cycle, thereby causing an arrest, which may be an irreversible process ultimately leading to apoptotic cell death. [7]. EGCG can also impede cell-to-cell contact adhesion and inhibit intracellular communication pathways which are required for cell division. Inhibition of proteasome by the ester bond-containing EGCG results in the accumulation of proteasome substrates p27 and IкB $\alpha$, followed by growth arrest in the G1 phase of the cellcycle, contributing to the cancer-preventive effects of tea. Another report suggests that inhibition of cell proliferation by EGCG may in part be mediated via modulation of the constitutive activation of PI3K/Akt [8] pathways as well as MEK-independent ERK1/2 activation [9].

Ahmad et al have observed that EGCG may mediate its cellular activity, at least in part, via targeting the kinase CK2 since down-regulation of CK2 sensitizes CaP cells to EGCGinducted apoptosis [10]. A recent study from our laboratory indicates that EGCG sensitizes TRAIL-resistant LNCaP cells to undergo apoptosis via modulating both intrinsic and extrinsic apoptotic pathways. Furthermore, treatment of cells with combination of EGCG and TRAIL resulted in synergistic inhibition of biomarkers associated with invasion, angiogenesis and metastasis [11]. There is evidence that EGCG exerts its cancer inhibitory effect through the 67-kDa laminin receptor that allows it to bind to the cell surface of cancer cells. This receptor is expressed on a variety of tumor cells, and its expression level strongly correlates with the risk of tumor invasion and metastasis [12]. Umeda et al showed recently that eEF1A, a G protein that delivers aminoacyl-tRNA to the elongating ribosome, is upregulated by EGCG through the laminin receptor and is crucial for EGCG-induced cancer prevention [13]. Bettuzzi et al. reported that EGCG treatment to CaP cells, but not normal cells, resulted in the induction of clusterin with cleavage of both pro-caspase 8 and procaspase 3, resulting in apoptosis of cancer cells. Moreover, the chemopreventive action of catechins in the TRAMP mouse model was also accompanied by overexpression of clusterin [14].

Studies show that EGCG effectively inhibits $5 \alpha$-reductase in cell-free assays, indicating that it can regulate androgen action in target organs. Replacement of the gallate ester in EGCG with long-chain fatty acids produces potent $5 \alpha$-reductase inhibitors that are active in both cell-free and whole-cell assay systems [15]. The attenuation of the androgen receptor (AR), AR regulated PSA and hK2 genes by EGCG in cell culture studies has also been reflected in in vivo models. It is well known that high level of IGF-1 with concomitant reduction in IGF binding protein (IGFBP)-3 are associated with increased risk for $\mathrm{CaP}$ development and its progression. TRAMP mice fed with green tea polyphenols exhibited significant inhibition of IGF-1 and restoration of IGFBP-3 with marked delay in $\mathrm{CaP}$ progression [16]. In addition, down-regulation of AR and insulin-like growth factor-1, modulation of inflammation biomarkers, and decrease in the MAPK signaling seen in EGCG treated mice may contribute to the reduction in cell proliferation and induction of apoptosis by EGCG and provide a biochemical basis for suppressing $\mathrm{CaP}$ without overt toxicity $[17,18]$. In addition, testosterone mediated induction of ornithine decarboxylase, an important contributor of $\mathrm{CaP}$ development, is inhibited by green tea polyphenols both under in vitro and in vivo situations [19].

Recent data suggest that the calcium-binding protein S100A4 represents a promising marker for $\mathrm{CaP}$ progression. Saleem et al showed that with progression of age and $\mathrm{CaP}$ growth, an increase in the expression of S100A4 at mRNA and protein level occured in the dorsolateral prostate of TRAMP, but not in nontransgenic mice. Green tea polyphenol feeding to TRAMP mice resulted in marked inhibition of $\mathrm{CaP}$ progression, with reduction of S100A4 
and restoration of E-cadherin [20]. This is important as S100A4 is overexpressed during the progression of $\mathrm{CaP}$ in humans and is thought to control the invasive potential of human $\mathrm{CaP}$ cells through the regulation of MMP-9 and its tissue inhibitor TIMP-1 [21].

Although in vitro research of the anticarcinogenic properties of EGCG seems promising, many diverse and unknown factors may influence its in vivo activity in animal and human models. Current data indicate that EGCG suppresses early stage, but not late stage $\mathrm{CaP}$ in TRAMP mice. In this context, ongoing studies in our laboratory suggest that the chemopreventive potential of green tea decreases with increasing tumor grade and underscores the need to identify the stage(s) of $\mathrm{CaP}$ development most vulnerable to chemopreventive intervention. [22].

Moreover, while epidemiological studies suggest that green tea compounds could protect against $\mathrm{CaP}$, existing data are inconsistent, and limitations in study design hinder full interpretation of the published observations. A case control study, conducted in southeast China during 2001 to 2002, reported a reduced CaP risk with increasing frequency, duration, and quantity of green tea consumption [23]. In another study, patients with asymptomatic androgen-independent metastatic prostate carcinoma and progressive PSA elevation were evaluated after ingestion of $6 \mathrm{~g}$ of green tea per day [24]. Only one patient manifested a decline in serum PSA, and no patient manifested a tumor response on radiographic assessment or physical examination. Thus, a limited antineoplastic effect with a maximum response rate of $2 \%$ was seen with green tea [24]. Similar results were observed in another clinical trial involving patients with hormone refractory $\mathrm{CaP}$. Green tea extract capsules, prescribed at a dose level of $250 \mathrm{mg}$ twice daily, showed minimal clinical activity against the disease [25]. Both these studies were conducted in end-stage disease, signifying that green tea may be more effective if used in the early stages of the disease or in patient at high risk. More recently, Bettuzzi et al. [26] have shown that after a year's p.o. administration of green tea catechins, only one man in a group of 32 with high-grade PIN developed $\mathrm{CaP}$ compared with 9 of 30 in the control group; a rate of only $3 \%$ in men developing the disease versus the expected rate of $30 \%$ in men treated with placebo. However, there is a need for large-scale, prospective, randomized trials to test the efficacy of green tea for the prevention and treatment of $\mathrm{CaP}$.

\subsection{Pomegranate}

Pomegranate, used for centuries for medicinal purposes, is the fruit of a deciduous shrub (Punica granatum) widely cultivated in the South Asian and Mediterranean region. The tree/ fruit can be divided into several anatomical compartments: seed; juice; peel; leaf; flower; bark; and roots; each of which has substantial pharmacologic activity [27]. A rich source of polyphenolic compounds, including anthocyanins and hydrolyzable tannins, pomegranate possesses a higher antioxidant activity than green tea and red wine [27]. Its juice, peel and oil, all have been reported to possess anticancer activities, including interference with tumor cell proliferation, invasion and angiogenesis. Albrecht et al showed that pomegranate extracts exhibited potent growth inhibitory activity against $\mathrm{CaP}$ cells along with induction of apoptosis [28]. Ellagic acid, caffeic acid, luteolin, and punicic acid, important components of the aqueous or the oily compartment of pomegranate fruit were reported to inhibit in vitro invasion of human PC-3 prostate cancer cells across matrigel membranes [29]. Another study showed that anatomically discrete sections of the pomegranate fruit acting synergistically exerted antiproliferative and antimetastatic effect against $\mathrm{CaP}$ cells. Here, invasion across matrigel by PC-3 prostate cancer cells was found to be inhibited after treatment with combinations of fermented pomegranate juice polyphenols, pomegranate peel polyphenols, and pomegranate seed oil, and the decrease in the invasive potential of $\mathrm{CaP}$ cells was measured as a function of the expression of phospholipase A2 [30]. Our laboratory aimed to discover the molecular basis of the anticancer activity of the pomegranate fruit. 
Employing Mass Spectrometry, pomegranate fruit extracted in our laboratory was found to contain six anthocyanins (pelargonidin 3-glucoside, cyanidin 3-glucoside, delphinidin 3glucoside, pelargonidin 3,5-diglucoside, cyaniding 3,5-diglucoside, and delphinidin 3,5diglucoside), ellagitannins, and hydrolysable tannins [31]. Using human prostate cancer cells, we next evaluated the antiproliferative and proapoptotic properties of pomegranate fruit extract both in vitro and in vivo. The dose-dependent inhibition of cell growth and viability was shown to be mediated through the cki-cyclin-cdk network with up-regulation of p21 and p27 during G1-phase arrest, independent of p53. This was accompanied with down-modulation of the cyclins D1, D2, and E and cdks -2, -4, and -6, operative in the G1 phase of the cell cycle [31]. Furthermore, oral administration of pomegranate fruit extract to athymic nude mice implanted with androgen-sensitive CWR22Rv1 cells resulted in significant inhibition in tumor growth concomitant with a decrease in serum PSA levels [31]. This data was corroborated by a recent report where significant inhibition of LAPC-4 $\mathrm{CaP}$ xenograft growth was observed by Seeram et al, in the SCID mouse model [32].

Ellagitannins, the most abundant polyphenols present in pomegranate juice are thought to contribute significantly towards its reported biological properties. It was shown that ellagitannin metabolites were concentrated at higher levels in the mouse prostate, colon, and intestinal tissues as compared to other tissues after administration of pomegranate extract [32]. Another report suggests that the anticancer activity of pomegranate may be through the prevention of procarcinogen activation mediated through the inhibition of CYP enzyme activity [33].

A phase II, Simon two-stage clinical trial for men with rising PSA after surgery or radiotherapy was recently conducted. Patients were treated with 8 ounces of pomegranate juice daily until disease progression. Clinical end points included safety and effect on serum PSA, serum-induced proliferation and apoptosis of LNCaP cells, serum lipid peroxidation, and serum nitric oxide levels. Patients were treated with 8 ounces of pomegranate juice daily until disease progression. The study showed that treatment with pomegranate juice was associated with statistically significant prolongation of PSA doubling time from a mean of 15 months at baseline to 54 months post treatment [34]. In vitro assays comparing pretreatment and post-treatment patient serum on the growth of LNCaP cells showed a $12 \%$ decrease in cell proliferation, $17 \%$ increase in apoptosis, $23 \%$ increase in serum nitric oxide, and significant reductions in oxidative state and sensitivity to oxidation of serum lipids after versus before pomegranate juice consumption [34]. No serious adverse effects were reported, and the treatment was well tolerated. These results are being further tested in a randomized, double-blind, three-arm, placebo-controlled study, which began in April 2006, and addresses several limitations of the current study, with the inclusion of two treatment arms in a dose-response design, as well as the use of a placebo control [34].

\subsection{Delphinidin}

Delphinidin, an anthocyanidin that gives bright hues to flowers like violas and delphiniums is also present in pomegranate, berries, grapes, beets and eggplant [35]. There is considerable evidence that delphinidin possesses potent anti-oxidant, anti-inflammatory and anti-angiogenic properties [35]. Ongoing work in our laboratory hints at the chemopreventive potential of delphinidin against various human cancers. Earlier, we had shown that delphinidin protects human $\mathrm{HaCaT}$ keratinocytes and mouse skin against UVBmediated oxidative stress and apoptosis [35]. As current chemotherapy is largely ineffective for $\mathrm{CaP}$ and has serious toxic side effects, we aimed to identify and develop novel, safe and naturally occurring agents that can target various intracellular signaling pathways deregulated in $\mathrm{CaP}$. Our studies show that delphinidin through modulations in the ckicyclin-cdk machinery, resulted in inhibition of cell growth followed by apoptosis of highly aggressive human prostate carcinoma PC-3 cells [36, 37]. The cell growth inhibition was 
associated with induction of cyclin kinase inhibitors p21 and p27, down-regulation of cyclin E, D1, and D2 and down-regulation of cdks $-2,-4$, and -6 . Moreover, this cell cycle arrest was accompanied by the induction of apoptosis with a downregulation of the antiapoptotic protein $\mathrm{Bcl}-2$ and increase in proapoptotic protein Bax, thus shifting the Bax:Bcl-2 ratio in favor of apoptosis. In addition, activation of caspases, with significant decreases in the protein expression of procaspase- $3,-6,-8$ and -9 and release of cytochrome $\mathrm{c}$ from the mitochondria to the cytosol indicated an essential role of caspases in delphinidin-mediated apoptosis of PC-3 cells [36].

Inhibition of $\mathrm{Wnt} / \beta$-catenin signaling pathway is an attractive target for new chemopreventive and chemotherapeutic approaches. The Wnt signaling pathway and its key component $\beta$-catenin play critical roles in embryonic development as well as in human diseases, including various malignancies. Since deregulation of $\beta$-catenin signaling pathway contributes to $\mathrm{CaP}$ progression, we examined the effect of delphinidin on $\beta$-catenin signaling pathway in human prostate cancer PC 3 cells. The canonical Wnt pathway consists of a series of events that occur when Wnt proteins bind to cell-surface receptors of the Frizzled family, causing the receptors to activate Dishevelled family proteins and ultimately resulting in a change in the amount of $\beta$-catenin that reaches the nucleus. Delphinidin treatment resulted in modulation of secreted Frizzled-related protein-3, low density lipoprotein receptor-related protein 6, Dickkopf and Dishevelled proteins [36]. Dishevelled, when activated by Wnt binding inhibits the axin/GSK3/APC complex involved in the proteolytic degradation of the $\beta$-catenin molecule. Delphinidin treatment of PC-3 cells resulted in the induction of phosphorylation of GSK3 $\beta$, and protein expression of APC and axin. In addition, delphinidin-mediated increase in the phosphorylation of $\beta$-catenin at serine and threonine residues resulted in increased degradation and decreased nuclear translocation of $\beta$-catenin. Stabilization of $\beta$-catenin and interaction with TCF/LEF family of transcription factors to promote specific gene expression was further inhibited by delphinidin as evidenced by decreased TCF-DNA binding activity with subsequent decrease in the expression of target genes cyclin D, c-myc and axin-2 [36]. Our data suggests that delphinidin could be useful as a potent inhibitor of $\mathrm{Wnt} / \beta$-catenin signaling in human $\mathrm{CaP}$ cells.

It is well established that WNT, Notch, FGF, and Hedgehog signaling pathways network together during embryogenesis, tissue regeneration, and carcinogenesis [38]. Indeed, increased Wnt signaling is known to trigger oncogenic conversion of human breast epithelial cells by a Notch-dependent mechanism [39]. Our studies showed that delphinidin-induced cell growth inhibition and apoptosis of human PC-3 cells is mediated, at least in part, through inhibition of Notch-1 and/or NF- $\mathrm{KB} / \mathrm{PI} 3 \mathrm{~K}$ pathways [37]. We found that delphinidin treatment to PC-3 cells resulted in inhibition of constitutive expression of Notch-1 alongwith inhibition of its active cleaved form. Overexpression of Hes-1, a down stream target of Notch-1 that promotes cell proliferation by repressing cell cycle inhibitory proteins is observed in various cancer cells including $\mathrm{CaP}$. We observed that delphinidin treatment to PC-3 cells resulted in inhibition of protein expression of Hes-1 suggesting deregulation of cell cycle by delphinidin [37]. The anti-apoptotic effects of Notch-1 proteins are known to be regulated through NF- $\mathrm{kB}$ signaling. In addition, studies show that increased NF- $\mathrm{BB}$ activity contributes directly to the invasive behavior of PC-3 CaP cells. Delphinidin treatment to PC-3 cells resulted in dose dependent inhibition of phosphorylation of upstream kinases IKK $\alpha$ and IKK $\gamma$ that regulate NF- $\mathrm{KB}$ activity, decrease in NF- $\mathrm{KB}$ inhibitory protein $\mathrm{I} \kappa \mathrm{B} \alpha$, with decrease in $\mathrm{NF}-\kappa \mathrm{B} / \mathrm{p} 50$ and $\mathrm{NF}-\kappa \mathrm{B} / \mathrm{p} 65$ protein expression and $\mathrm{NF}-\kappa \mathrm{B} / \mathrm{p} 50$ and $\mathrm{NF}-\mathrm{\kappa B} / \mathrm{p} 65$ DNA binding activities suggesting inhibition of NF- $\mathrm{KB}$ at the transcription level [37]. Acquired mutations of the PTEN gene reported in up to 30-60\% of prostate cancer tumors results in constitutive activation of the PI3K/Akt pathway which then represents a major target to prevent dysfunctions in cell growth, survival and motility. Delphinidin treatment to PC-3 cells significantly inhibited p110 (catalytic) and p85 (regulatory) subunits 
of PI3K, an essential downstream regulator of growth signaling pathways [37]. In summary, delphindin seems to act as a multifunctional anticancer agent in in vitro studies. However thoughtfully designed clinical trials are necessary to reveal the possible benefits of this agent in preventing tumor development and malignant progression.

\subsection{Lupeol}

Lup-20(29)-en-3 $\beta$-ol (Lupeol) is a triterpene found in fruits such as olives, mangoes, strawberries, grapes, and figs, vegetables, and several medicinal plants [40]. It possesses strong anti-inflammatory, antiarthritic, antimutagenic, and antimalarial activity and has been used for the treatment of various diseases [40]. Recent data from our laboratory and others suggest that lupeol possesses potent anti-cancer activities in vitro and in vivo systems [41]. We have shown that lupeol treatment resulted in significant inhibition of cell viability of LNCaP and CWR22Rv1 androgen-sensitive prostate cancer cells with minimal effect on normal prostate epithelial cells [41]. Lupeol-induced apoptosis in these cells was associated with cleavage of poly(ADP-ribose) polymerase protein and degradation of acinus protein. Moreover, lupeol increases the expression of the death receptor Fas along with upregulation of the adaptor protein FADD, required for the recruitment and activation of procaspase 8 to form the death inducing signaling complex. The small interfering RNA-mediated silencing of the Fas gene and inhibition of caspase- 6 , caspase- 8 , and caspase- 9 by their specific inhibitors further confirmed that lupeol specifically activates the Fas receptor-mediated apoptotic pathway [41]. Furthermore, combination of anti-Fas monoclonal antibody and lupeol resulted in higher cell death compared with the additive effect of the two compounds alone, suggesting a synergistic effect that can be exploited against $\mathrm{CaP}$. In mice xenograft model, lupeol treatment significantly inhibited the growth of CWR22Rv1 tumor cells with concomitant reduction in PSA secretion [41].

Prasad et al have also shown that lupeol exerts protective effect against androgen-induced oxidative stress. Oral treatment of lupeol and mango pulp extract to testosterone injected Swiss albino mice resulted in inhibition of testosterone-induced increase in the levels of reactive oxygen species, depletion of antioxidant enzymes such as catalase and superoxide dismutase, and increase in lipid peroxidation in the murine prostate [42].

We recently investigated the mechanistic basis of the multi-targeted effect of lupeol in $\mathrm{CaP}$ cells. Lupeol treatment was observed to inhibit the proliferative and clonogenic potential of $\mathrm{CaP}$ cells with reduced expression level of PCNA protein, a marker of cell proliferation [43]. Microarray studies further showed that lupeol significantly modulated the expression of genes known to be associated with proliferation and survival. Lupeol treatment decreased the mRNA expression level of insulin-like growth factor-1 receptor (IGF-1R), myc, cyclin D1, ERBB2 and Jun, and caused an increase in the mRNA expression level of IGFBP6, STEAP1, TIMP3 and KLK10. Lupeol-induced modulations in the mRNA expression levels of these genes corroborated well with their protein expressions [43]. Genes modulated by lupeol are known to be associated directly or indirectly with $\beta$-catenin signaling, highly aberrant in CaP. Predictably, lupeol reduced the cellular levels of $\beta$-catenin with an increase in the GSK3 $\beta$ /Axin destruction complex, concomitant with significant reduction in the transcriptional activation of the TCF. Finally, lupeol-mediated downregulation of matrix metalloproteinases -2 and -7 relates to the ability of the agent to effectively target the IGF-1R/ $\beta$-catenin axis leading to the inhibition of proliferation of $\mathrm{CaP}$ cells [43]. Ongoing animal experiments will shed more light on the chemopreventive potential of the agent against $\mathrm{CaP}$. 


\subsection{Fisetin}

Fisetin, or 3,7,3',4'-tetrahydroxyflavone, belongs to flavonol subgroup of flavonoids together with quercetin, myricetin and kaempferol. Fisetin can be found in many fruits such as strawberries, apple, persimmon, kiwi fruit and vegetables including onion and cucumber [44]. Cell culture studies show that fisetin exerts antiproliferative effect on human CaP cells. Data from our laboratory indicate that fisetin selectively decreases the viability of LNCaP, CWR22Rv1 and PC-3 CaP but has only minimal effect on normal prostate epithelial cells [44]. Flowcytometric analysis indicated that the cell cycle arrest observed in PC3 cells was in $\mathrm{G} 2 / \mathrm{M}$ phase whereas the $\mathrm{LNCaP}$ cells demonstrated a different cell cycle profile [45]. We showed that treatment of LNCaP cells with fisetin induced arrest in the G1 phase of the cell cycle, accompanied with decreased level of cyclins and cdks and concomitant induction of p21 and p27. Furthermore, fisetin mediated apoptosis was associated with the release of mitochondrial cytochrome $c$ into the cytosol [44]. Cytochrome $c$, Apaf-1, adenosine triphosphate and procaspase- 9 are known to form a supramolecular complex termed apoptosome that activates caspase- 9 through autocatalysis. The mitochondrial-activated caspase- 9 and the death receptor-activated caspase- 8 cleave the procaspase- 3 and generate the active caspase- 3 that serves as the central executioner of apoptosis. Fisetin treatment resulted in significant activation of caspases $-3,-8$ and -9 in CaP cells. The caspase pathway is regulated by inhibitors of apoptosis protein (IAP) but during apoptosis, inhibitory effects of IAPs are neutralized by the second mitochondria-derived activator of caspase (Smac), direct IAP-binding protein with low $\mathrm{pI}$ (DIABLO) and/or high-temperature requirement protein-A2, which are released from mitochondria. Fisetin treatment resulted in the downregulation of XIAP and upregulation of Smac/DIABLO alongwith modulation in the expression of Bcl 2 family proteins, critical regulators of the apoptotic pathway [44]. This indicates that fisetin can alter the mitochondrial membrane function of $\mathrm{CaP}$ cells thereby inducing apoptosis, an important molecular target for chemoprevention of cancer.

A recent study indicated that inhibition of uPA by fisetin [45] in the advancing capillary vessels surrounding the tumor may be responsible for reducing angiogenesis and consequently tumor growth. In addition, fisetin and other flavonoids that contain a catechol group have been shown to be potent inhibitors of the type $15 \alpha$-reductase [46]. It is thought that since these compounds are consumed as part of the normal diet or in supplements, they have the potential to inhibit $5 \alpha$-reductase activity, which may be useful for the prevention or treatment of androgen-dependent disorders including cancer. Collectively these data provide the first evidence that fisetin could be developed as an effective agent against $\mathrm{CaP}$.

\section{Conclusions}

The future role of dietary supplements in $\mathrm{CaP}$ is of much interest, and preliminary data are noteworthy. Regardless, unresolved issues still linger. For most cancer interventions, the expected time to achieve an effect is much longer, more variable, and far less well understood, and the progression of disease is hard to follow. In addition, the optimal dose and duration needed to test nutritional agents for cancer prevention are largely unidentified, making null findings hard to interpret. Baseline nutritional status can be critical. In addition, particular nutrients may be effective only in subgroups defined by genotypes or by nutritional status of another nutrient. Therefore, before these agents can be recommended as useful chemopreventive strategies for patients, there is a need to confirm their activity in rigorous well designed clinical trials.

\section{References}

1. American Cancer society. Cancer facts and figures. 2007. www.cancer.org 
2. Kakizoe T. Chemoprevention of cancer-focusing on clinical trials. Cancer Res. 2004; 64:19-22. [PubMed: 14729601]

3. Hughes C, Murphy A, Martin C, Sheils O, O'Leary J. Molecular pathology of prostate cancer. J Clin Pathol. 2005; 58:673-684. [PubMed: 15976331]

4. Syed DN, Khan N, Afaq F, Mukhtar H. Chemoprevention of prostate cancer through dietary agents: progress and promise. Cancer Epidemiol Biomarkers Prev. 2007; 16:2193-2203. [PubMed: 18006906]

5. Carlson JR, Bauer BA, Vincent A, Limburg PJ, Wilson T. Reading the tea leaves: anticarcinogenic properties of (-)-epigallocatechin-3-gallate. Mayo Clin Proc. 2007; 82:725-732. [PubMed: 17550753]

6. Adhami VM, Ahmad N, Mukhtar H. Molecular targets for green tea in CaP prevention. J Nutr. 2003; 133:2417S-2424S. [PubMed: 12840218]

7. Gupta S, Hussain T, Mukhtar H. Molecular pathway for (-)-epigallocatechin-3-gallate-induced cell cycle arrest and apoptosis of human prostate carcinoma cells. Arch Biochem Biophys. 2003; 410:177-185. [PubMed: 12559991]

8. Siddiqui IA, Adhami VM, Afaq F, Ahmad N, Mukhtar H. Modulation of phosphatidylinositol-3kinase/protein kinase B- and mitogen-activated protein kinase-pathways by tea polyphenols in human prostate cancer cells. J Cell Biochem. 2004; 91:232-242. [PubMed: 14743383]

9. Albrecht DS, Clubbs EA, Ferruzzi M, Bomser JA. Epigallocatechin-3-gallate (EGCG) inhibits PC-3 prostate cancer cell proliferation via MEK-independent ERK1/2 activation. Chem Biol Interact. 2008; 171:89-95. [PubMed: 17931610]

10. Ahmad KA, Harris NH, Johnson AD, Lindvall HC, Wang G, Ahmed K. Protein kinase CK2 modulates apoptosis induced by resveratrol and epigallocatechin-3-gallate in prostate cancer cells. Mol Cancer Ther. 2007; 6:1006-1012. [PubMed: 17363494]

11. Siddiqui IA, Malik A, Adhami VM, Asim M, Hafeez BB, Sarfaraz S, et al. Green tea polyphenol EGCG sensitizes human prostate carcinoma LNCaP cells to TRAIL-mediated apoptosis and synergistically inhibits biomarkers associated with angiogenesis and metastasis. Oncogene. 2007 [Epub ahead of print].

12. Umeda D, Tachibana H, Yamada K. Epigallocatechin-3-O-gallate disrupts stress fibers and the contractile ring by reducing myosin regulatory light chain phosphorylation mediated through the target molecule 67 kDa laminin receptor. Biochem Biophys Res Commun. 2005; 333:628-635. [PubMed: 15946647]

13. Umeda D, Yano S, Yamada K, Tachibana H. Green tea polyphenol epigallocatechin-3-gallate (EGCG) signaling pathway through 67-kDa laminin receptor. J Biol Chem. 2007 [Epub ahead of print].

14. Caporali A, Davalli P, Astancolle S, D'Arca D, Brausi M, Bettuzzi S, et al. The chemopreventive action of catechins in the TRAMP mouse model of prostate carcinogenesis is accompanied by clusterin over-expression. Carcinogenesis. 2004; 25:2217-2224. [PubMed: 15358631]

15. Liao S, Hiipakka RA. Selective inhibition of steroid 5 $\alpha$-reductase isozymes by tea epicatechin-3gallate and epigallocatechin-3-gallate. Biochem Biophys Res Commun. 1995; 214:833-838. [PubMed: 7575552]

16. Adhami VM, Siddiqui IA, Ahmad N, Gupta S, Mukhtar H. Oral consumption of green tea polyphenols inhibits insulin-like growth factor-I-induced signaling in an autochthonous mouse model of CaP. Cancer Res. 2004; 64:8715-8722. [PubMed: 15574782]

17. Harper CE, Patel BB, Wang J, Eltoum IA, Lamartiniere CA. Epigallocatechin-3-Gallate suppresses early stage, but not late stage prostate cancer in TRAMP mice: mechanisms of action. Prostate. 2007; 67:1576-1589. [PubMed: 17705241]

18. Adhami VM, Malik A, Zaman N, Sarfaraz S, Siddiqui IA, Syed DN, et al. Combined inhibitory effects of green tea polyphenols and selective cyclooxygenase-2 inhibitors on the growth of human prostate cancer cells both in vitro and in vivo. Clin Cancer Res. 2007; 13:1611-1619. [PubMed: 17332308]

19. Gupta S, Ahmad N, Mohan RR, Husain MM, Mukhtar H. CaP chemoprevention by green tea: in vitro and in vivo inhibition of testosterone-mediated induction of ornithine decarboxylase. Cancer Res. 1999; 59:2115-2120. [PubMed: 10232597] 
20. Saleem M, Adhami VM, Ahmad N, Gupta S, Mukhtar H. Prognostic significance of metastasisassociated protein S100A4 (Mts1) in CaP progression and chemoprevention regimens in an autochthonous mouse model. Clin Cancer Res. 2005; 11:147-153. [PubMed: 15671539]

21. Saleem M, Kweon MH, Johnson JJ, Adhami VM, Elcheva I, Khan N, et al. S100A4 accelerates tumorigenesis and invasion of human prostate cancer through the transcriptional regulation of matrix metalloproteinase 9. Proc Natl Acad Sci U S A. 2006; 103:14825-14830. [PubMed: 16990429]

22. Adhami, VM.; Siddiqui, IA.; Sarfaraz, S.; Khwaja, SI.; Mukhtar, H. Efficacious prostate cancer chemopreventive intervention with green tea polyphenols decreases with increasing tumor grade in the autochthonous transgenic TRAMP model. Annual Meeting of the American Association for Cancer Research; San Diego, CA, U.S.A. 2008. p. 08-AB-5532-AACR

23. Jian L, Xie LP, Lee AH, Binns CW. Protective effect of green tea against CaP: a case-control study in southeast China. Int J Cancer. 2004; 108:130-135. [PubMed: 14618627]

24. Jatoi A, Ellison N, Burch PA, Sloan JA, Dakhil SR, Novotny P, et al. A phase II trial of green tea in the treatment of patients with androgen independent metastatic prostate carcinoma. Cancer. 2003; 97:1442-1446. [PubMed: 12627508]

25. Choan E, Segal R, Jonker D, Malone S, Reaume N, Eapen L, et al. A prospective clinical trial of green tea for hormone refractory $\mathrm{CaP}$ : an evaluation of the complementary/alternative therapy approach. Urol Oncol. 2005; 23:108-113. [PubMed: 15869995]

26. Bettuzzi S, Brausi M, Rizzi F, Castagnetti G, Peracchia G, Corti A. Chemoprevention of human prostate cancer by oral administration of green tea catechins in volunteers with high-grade prostate intraepithelial neoplasia: a preliminary report from a one-year proof-of-principle study. Cancer Res. 2006; 66:1234-1240. [PubMed: 16424063]

27. Lansky EP, Newman RA. Punica granatum (pomegranate) and its potential for prevention and treatment of inflammation and cancer. J Ethnopharmacol. 2007; 109:177-206. [PubMed: 17157465]

28. Albrecht M, Jiang W, Kumi-Diaka J, Lansky EP, Gommersall LM, Patel A, et al. Pomegranate extracts potently suppress proliferation, xenograft growth, and invasion of human prostate cancer cells. J Med Food. 2004; 7:274-283. [PubMed: 15383219]

29. Lansky EP, Harrison G, Froom P, Jiang WG. Pomegranate (Punica granatum) pure chemicals show possible synergistic inhibition of human PC-3 prostate cancer cell invasion across Matrigel. Invest New Drugs. 2005; 23:121-122. [PubMed: 15744587]

30. Lansky EP, Jiang W, Mo H, Bravo L, Froom P, Yu W, et al. Possible synergistic prostate cancer suppression by anatomically discrete pomegranate fractions. Invest New Drugs. 2005; 23:11-20. [PubMed: 15528976]

31. Malik A, Afaq F, Sarfaraz S, Adhami VM, Syed DN, Mukhtar H. Pomegranate fruit juice for chemoprevention and chemotherapy of prostate cancer. Proc Natl Acad Sci U S A. 2005; 102:14813-14818. [PubMed: 16192356]

32. Seeram NP, Aronson WJ, Zhang Y, Henning SM, Moro A, Lee RP, et al. Pomegranate ellagitannin-derived metabolites inhibit prostate cancer growth and localize to the mouse prostate gland. J Agric Food Chem. 2007; 55:7732-7737. [PubMed: 17722872]

33. Faria A, Monteiro R, Azevedo I, Calhau C. Pomegranate juice effects on cytochrome p450s expression: in vivo studies. J Med Food. 2007; 10:643-649. [PubMed: 18158835]

34. Pantuck AJ, Leppert JT, Zomorodian N, Aronson W, Hong J, Barnard RJ, et al. Phase II study of pomegranate juice for men with rising prostate-specific antigen following surgery or radiation for prostate cancer. Clin Cancer Res. 2006; 12:4018-4026. [PubMed: 16818701]

35. Afaq F, Syed DN, Malik A, Hadi N, Sarfaraz S, Kweon MH, et al. Delphinidin, an anthocyanidin in pigmented fruits and vegetables, protects human HaCaT keratinocytes and mouse skin against UVB-mediated oxidative stress and apoptosis. J Invest Dermatol. 2007; 127:222-232. [PubMed: 16902416]

36. Yun, JM.; Afaq, F.; Mukhtar, H. Dietary anthocyanidin delphinidn modulates $\beta$-catenin signaling pathway in human prostate cancer PC-3 cells. Annual Meeting of the American Association for Cancer Research; San Diego, CA, U.S.A. 2008. p. 08-AB-5381-AACR 
37. Mukhtar, H.; Adhami, VM.; Afaq, F.; Saleem, M.; Sarfaraz, S.; Khan, N., et al. Delphinidin induces apoptosis and growth inhibition of prostate cancer PC-3 cells via inhibition of Notch-1 and NF- $\kappa \mathrm{B} / \mathrm{PI} 3 \mathrm{~K}$ pathways. The Centennial Annual Meeting of the American Association for Cancer Research; Los Angeles, CA, U.S.A. 2007. p. 375

38. Katoh M. Networking of WNT, FGF, Notch, BMP, and Hedgehog signaling pathways during carcinogenesis. Stem Cell Rev. 2007; 3:30-38. [PubMed: 17873379]

39. Ayyanan A, Civenni G, Ciarloni L, Morel C, Mueller N, Lefort K, et al. Increased Wnt signaling triggers oncogenic conversion of human breast epithelial cells by a Notch-dependent mechanism. Proc Natl Acad Sci U S A. 2006; 103:3799-3804. [PubMed: 16501043]

40. Khan N, Afaq F, Mukhtar H. Cancer chemoprevention through dietary antioxidants: Progress and Promise. Antioxid Redox Signal. 2007 [Epub ahead of print].

41. Saleem M, Kweon MH, Yun JM, Adhami VM, Khan N, Syed DN, et al. A novel dietary triterpene Lupeol induces fas-mediated apoptotic death of androgen-sensitive prostate cancer cells and inhibits tumor growth in a xenograft model. Cancer Res. 2005; 65:11203-11213. [PubMed: 16322271]

42. Prasad S, Kalra N, Singh M, Shukla Y. Protective effects of lupeol and mango extract against androgen induced oxidative stress in Swiss albino mice. Asian J Androl. 2007 [Epub ahead of print].

43. Saleem, M.; Suh, Y.; Hafeez, BB.; Johnson, JJ.; Kweon, MH.; Murtaza, I.; Mukhtar, H. Lupeol, a novel diet-based triterpene modulates insulin growth factor receptor 1 and $\beta$-catenin signaling in human prostate cancer cells. Annual Meeting of the American Association for Cancer Research; San Diego, CA, U.S.A. 2008. p. 08-AB-5381-AACR

44. Khan, N.; Afaq, F.; Syed, DN.; Mukhtar, H. Fisetin, a novel dietary flavonoid causes apoptosis and cell- cycle arrest in human prostate cancer LNCaP cells. Annual Meeting of the American Association for Cancer Research; San Diego, CA, U.S.A. 2008. p. 08-AB-2152-AACR

45. Haddad AQ, Venkateswaran V, Viswanathan L, Teahan SJ, Fleshner NE, Klotz LH. Novel antiproliferative flavonoids induce cell cycle arrest in human prostate cancer cell lines. Prostate Cancer Prostatic Dis. 2006; 9:68-76. [PubMed: 16314891]

46. Jankun J, Selman SH, Aniola J, Skrzypczak-Jankun E. Nutraceutical inhibitors of urokinase: potential applications in prostate cancer prevention and treatment. Oncol Rep. 2006; 16:341-346. [PubMed: 16820913]

47. Hiipakka RA, Zhang HZ, Dai W, Dai Q, Liao S. Structure-activity relationships for inhibition of human $5 \alpha$-reductases by polyphenols. Biochem Pharmacol. 2002; 63:1165-1176. [PubMed: 11931850] 
Table 1

\section{Multiple effects of dietary agents against prostate cancer}

\begin{tabular}{|c|c|c|c|}
\hline Dietary agent & In vitro studies & In vivo studies & Clinical trials \\
\hline Green Tea & $\begin{array}{l}\text { Inhibits cell growth, induces apoptosis, increases } \mathrm{p} 21, \mathrm{p} 53 \text {, and Bax } \\
\text { [6], inhibits HIF-1 } \alpha \text { degradation, inhibits biomarkers of invasion, } \\
\text { angiogenesis and metastasis, inhibits PSA-triggered basement } \\
\text { membrane degradation, and MMP-2 activation [4], inhibits } 5 \alpha- \\
\text { reductase [15] and ODC activity [19], downregulates CK2 [10], } \\
\text { sensitizes CaP cells to TRAIL-mediated apoptosis [11], upregulates } \\
\text { eEF1A through laminin receptor [13] }\end{array}$ & $\begin{array}{l}\text { Induces clusterin [14], } \\
\text { decreases IGF-I and increases } \\
\text { IGFBP-3 levels, inhibits } \\
\text { tumor growth and PSA } \\
\text { secretion [16], reduces CaP } \\
\text { progression with decrease in } \\
\text { S100A4 and restoration of E- } \\
\text { cadherin [20] }\end{array}$ & $\begin{array}{l}\text { Reduces risk of } \\
\text { CaP }[23,26] \\
\text { Shows minimal } \\
\text { activity against } \\
\mathrm{CaP}[24,25]\end{array}$ \\
\hline Pomegranate & $\begin{array}{l}\text { Exerts antiproliferative, antiinvasive, antimetastatic effects [28, 29, } \\
\text { 31], induces apoptosis through modulation of Bcl2 proteins [31], } \\
\text { increases p21\&p27, downregulates cyclin-cdk network [31] }\end{array}$ & $\begin{array}{l}\text { Decreases tumor incidence, } \\
\text { tumor growth and serum PSA } \\
\text { levels }[28,31]\end{array}$ & $\begin{array}{l}\text { Increases PSA } \\
\text { doubling time [34] }\end{array}$ \\
\hline Delphinidin & $\begin{array}{l}\text { Exerts antiproliferative effects, induces cell cycle arrest, increases p } 21 \\
\text { and p27, downregulates cyclin-cdk network, modulates Bcl2 poteins } \\
\text { in favor of apoptosis, releases cyt } c \text {, activates Caspases-3,-6,-8\&-9, } \\
\text { downregulates PI3K, } \beta \text {-catenin, Notch, and NF-kB signaling }[36,37]\end{array}$ & & \\
\hline Lupeol & $\begin{array}{l}\text { Induces apoptosis, upregulates Fas \& FADD, activates Caspase-8 } \\
\text { with degradation of acinus and PARP [41], downregulates IGF1-R, } \\
\text { myc, cyclin D1, ERBB2, Jun, MMPs -2\&7, upregulates IGFBP6, } \\
\text { STEAP1, TIMP3, and KLK10, downregulates } \beta \text {-catenin signaling } \\
\text { [43] }\end{array}$ & $\begin{array}{l}\text { Inhibits tumor growth and } \\
\text { PSA secretion [41], inhibits } \\
\text { testosterone-induced } \\
\text { generation of ROS, depletes } \\
\text { antioxidant enzymes [42] }\end{array}$ & \\
\hline Fisetin & $\begin{array}{l}\text { Exerts antiproliferative effects, induces cell cycle arrest, increases } \\
\text { p21\& p27, downregulates cyclin-cdk network, induces apoptosis, } \\
\text { modulates Bc12 proteins, releases cyt } c \text {, downregulates XIAP, } \\
\text { upregulates Smac/DIABLO, activates Caspases-3,-8\&-9, induces } \\
\text { PARP cleavage [44], inhibits 5 } \alpha \text {-reductase [47] and uPA [46] }\end{array}$ & & \\
\hline
\end{tabular}

